\title{
Prediction of daily suspended sediment load using wavelet and neuro- fuzzy combined model
}

\author{
${ }^{1}$ T. Rajaee; ${ }^{1 *}$ S. A. Mirbagheri; ${ }^{2}$ V. Nourani; ${ }^{3}$ A. Alikhani \\ ${ }^{1}$ Department of Civil Engineering, K.N. Toosi University of Technology, Tehran, Iran \\ ${ }^{2}$ Faculty of Civil Engineering, University of Tabriz, Tabriz, Iran \\ ${ }^{3}$ Deptartment of Civil Engineering, University of Qom, Qom, Iran
}

Received 27 December 2008; $\quad$ revised 18 April 2009; accepted 1 November 2009; available online 1 December 2009

\begin{abstract}
This study investigated the prediction of suspended sediment load in a gauging station in the USA by neuro-fuzzy, conjunction of wavelet analysis and neuro-fuzzy as well as conventional sediment rating curve models. In the proposed wavelet analysis and neuro-fuzzy model, observed time series of river discharge and suspended sediment load were decomposed at different scales by wavelet analysis. Then, total effective time series of discharge and suspended sediment load were imposed as inputs to the neuro-fuzzy model for prediction of suspended sediment load in one day ahead. Results showed that the wavelet analysis and neuro-fuzzy model performance was better in prediction rather than the neuro-fuzzy and sediment rating curve models. The wavelet analysis and neuro-fuzzy model produced reasonable predictions for the extreme values. Furthermore, the cumulative suspended sediment load estimated by this technique was closer to the actual data than the others one. Also, the model could be employed to simulate hysteresis phenomenon, while sediment rating curve method is incapable in this event.
\end{abstract}

Keywords: Artificial intelligence; Hysteresis; Modeling; Sediment rating curve; Wavelet decomposition

\section{INTRODUCTION}

The sediment load transported in river is the most complex hydrological and environmental phenomenon due to the large number of obscure parameters such as spatial variability of basin characteristics and river discharge patterns. In most rivers, sediments are mainly transported as suspended sediment load (SSL) (Morris and Fan, 1997). Many models have been provided to simulate this phenomenon (Mirbagheri et al., 1988a, b; Verstraeten and Poesen, 2001). Due to large number of obscure parameters involved in this phenomenon, the theoretical governing equations may not be of much advantage in gaining knowledge of the overall process. Studies have been made to develop artificial intelligence techniques for simulation processes with limited adequate knowledge of the physics (Rajaee and Mirbagheri, 2009; Nourani et al., 2008a). In the previous years, the fuzzy logic has been used in the simulation of uncertainties in the water resources and environmental engineering such as river pollution management (Nasiri et al., 2007), centralized return centers location evaluation in a reverse logistics network (Tuzkaya and Gülsün, 2008) environmental performance evaluation of

ه *Corresponding Author Email: mirbagheri@kntu.ac.ir Tel.: +9821 8877 9473; Fax: +9821 88035516 suppliers (Tuzkaya et al., 2009) and integrated water systems modeling (Nguyen et al., 2007). Artificial neural networks have been successfully applied to many tasks in environmental engineering (Bandyopadhyay and Chattopadhyay, 2007; Rene et al., 2008). Neuro-fuzzy modeling is another method that refers to the approach of applying deferent learning algorithms developed in the neural network literature to fuzzy modeling or a fuzzy inference system (FIS) (Brown and Harris, 1994). Neurofuzzy model (NF) has been applied to a number of problems in water resources and environmental engineering, including river flow modeling (ZounematKermani and Teshnehlab, 2008), predicting and identifying traffic hot spots (Hadji Hosseinlou and Sohrabi, 2009), hydrological time series modeling (Firat and Gungor, 2008) and ecological status modeling in surface waters (Ocampo et al., 2007). There are a few researches in employment of fuzzy inference system and neuro-fuzzy approaches in suspended sediment modeling. Tayfur et al. (2003) provided a fuzzy logic method using the rainfall intensity and slope data to predict sediment loads from bare soil surfaces. The research showed that the fuzzy approach performed better under very high rainfall intensities over different 
slopes and over very steep slopes under various rainfall intensities. Lohani et al. (2007) developed a fuzzy inference system to simulate the stage-dischargesediment concentration relationship in two gauging stations in the Narmada basin in India. Results of the mentioned study showed that the fuzzy method was capable to provide much better results than rating curve method. Kisi et al. (2008) studied the accuracy of an adaptive neuro-fuzzy computing method in monthly suspended sediment estimation in Kuylus and Salur Koprusu stations in Turkey. The results showed that NF model produced better performance than artificial neural network (ANN) and SRC models. In Rajaee et al. (2009), NF, ANN, multi linear regression and SRC models were examined for daily simulation of suspended sediment concentration in two hydrometery stations. The models were trained using daily river discharge and sediment concentration data belonging to Little Black River and Salt River stations in the USA. Comparison of the models' results indicated that the NF model was more accurate in predicting sediment concentration in comparison with the other models.

A wavelet analysis is a set of building blocks to build or represent a signal or function. It has increased in practice and popularity in latest years. Wavelet analysis, which give information in both the time and frequency domains of the signal, give considerable knowledge about the physical form of the data. It supplies a timefrequency representation of a signal at many different periods in the time domain (Daubechies, 1990). Wavelet transformed data of original time series improve the ability of a predicting model by capturing useful information on various resolution levels (Kim and Valdes, 2003). An inclusive literature overview of wavelet analysis in geosciences can be found in FoufoulaGeorgiou and Kumar (1995) and the most recent contributions are cited by Labat (2005). In the past few years, wavelet analysis has been employed to problems in water resources and environmental engineering, including river flow modeling (Pasquini and Depetris, 2007), meteorological pollution simulation (Osowski and Garanty, 2007), open channel wake flows analysis (Addison et al., 2001) and groundwater level time series modeling (Wang and Ding, 2003).

Wavelet analysis and artificial intelligent approaches (such as FIS and NF) are indicated to be suitable when applied individually to environmental and water resources problems. Recently, there has been a growing interest in combining methods. Partal and Kisi (2007) developed a wavelet and neuro-fuzzy conjunction model for daily precipitation forecasting in Turkey. Their neurofuzzy model is constructed with appropriate wavelet subseries as input and original precipitation as output. The provided wavelet-neuro-fuzzy model well fit with the measured data, particularly for zero and peaks precipitation time series. Results showed that the provided model produced significantly better results than neuro-fuzzy approach. Nourani et al. (2008b) proposed a combined neural-wavelet model. In their research, the wavelet analysis was linked to ANN for prediction of Ligvanchai watershed precipitation at Tabriz- Iran. For this purpose, the main time series was decomposed to some multi-frequently time series by wavelet. Then, these time series were imposed as input data to the ANN to predict the precipitation of one month ahead. The obtained results showed that the proposed model can predict both short and long term precipitation events because of using multi-scale time series as the ANN input layer. Wei et al. (2009) provided a wavelet network approach for modeling of a permeate flux of cross-flow membrane filtration. The aim of this research is to construct a new model based on wavelet transform and adaptive neuro-fuzzy approach for suspended sediment load prediction in Pecos gauging station in the USA. The purpose of combining the wavelet analysis with NF technique is to increase the accuracy of SSL prediction.

\section{MATERIALS AND METHODS}

Study area and statistical analysis

The proposed NF and wavelet analysis and neurofuzzy (WNF) models need uninterrupted time series data pertaining to river discharge $(Q)$ and SSL $(S)$ at a gauging station. The data obtained from the Pecos River near Artesia, NM (USGS Station No: 08396500, Basin area (sq. mi.): 15300 , Latitude: $32^{\circ} 50^{\prime} 25^{\prime \prime}$ and Longitude: $104^{\circ}$ 19’23") was used for calibration and verification for all the models provided in this study. The Pecos River is situated in eastern New Mexico and western Texas. There are primarily two major water inputs, namely snowmelt from winter storms in the headwater region of the southern Rocky Mountains and runoff from warmseason monsoonal rainfall in the lower valley. This river has been the subject of investigation by Yuan et al., (2007). Fig. 1 shows the state and the gauging station.

The data from October 1, 1965 to September 30, 1972 (7 years) and the data from October 1, 1972 to September 30, 1974 (2 years) were used for calibration and verification sets, respectively. The data statistics for training and testing sets are given in Table 1, which contain the minimum, maximum, mean, standard 


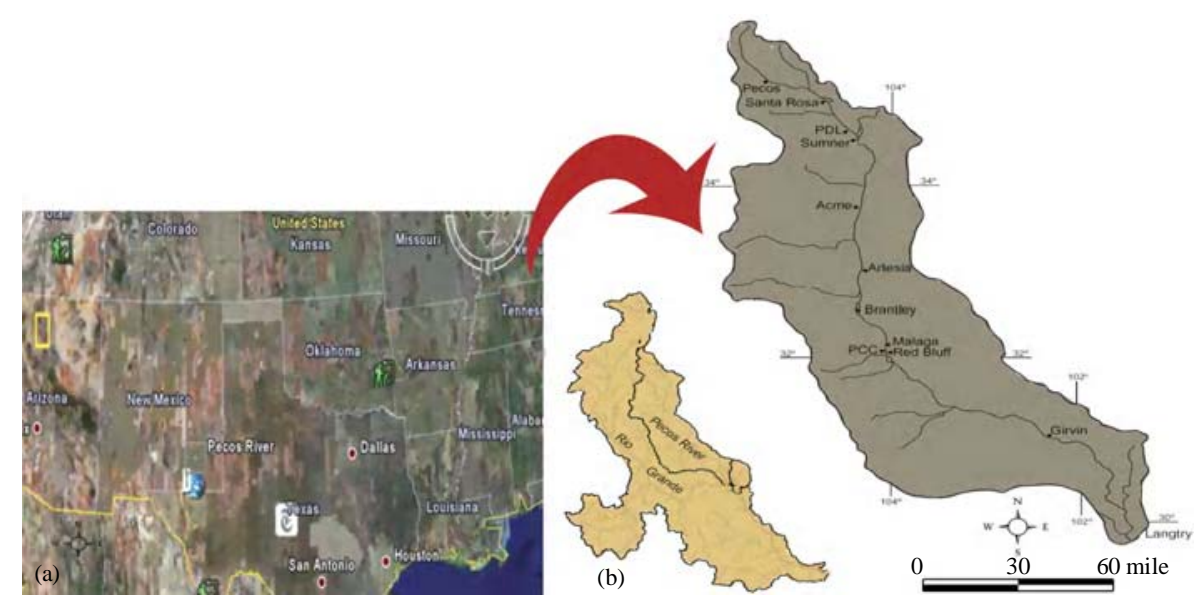

Fig. 1: (a) New Mexico State, (b) Drainage map showing the Pecos River and its adjacent areas
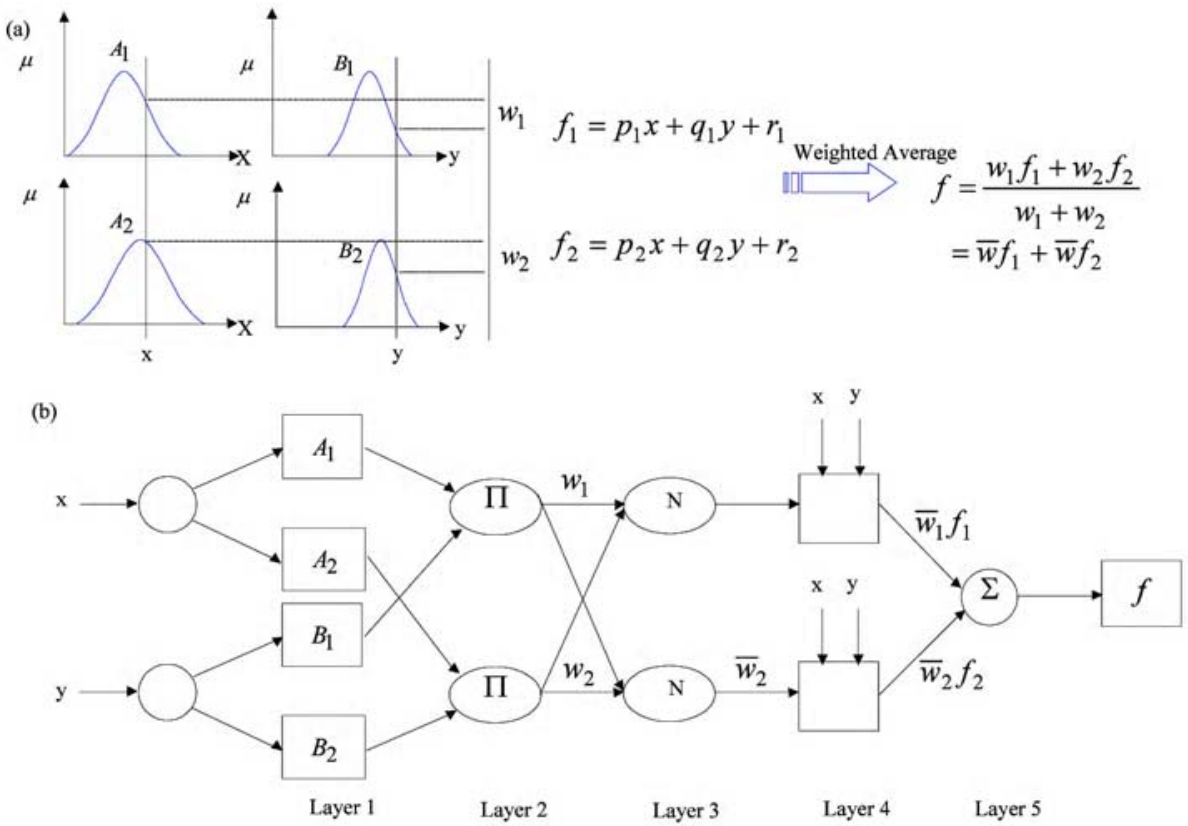

Fig. 2: Structure of ANFIS system: (a) Fuzzy inference system; (b) Equivalent ANFIS architecture

deviation $\left(S_{d}\right)$, skewness coefficient $\left(C_{s x}\right)$, lag 1 day autocorrelation coefficient $\left(R_{1}\right)$, lag 2 days autocorrelation coefficient $\left(R_{2}\right)$ and lag 3 days autocorrelation coefficient $\left(R_{3}\right)$.

From Table 1, it is obvious that the extreme values of the available data are in the training set. When classifying the data into training and testing subsets, it is essential to check that the data represent the same statistical population (Masters, 1993). Discharge and SSL lag 1 day autocorrelation coefficients are very adequate and relatively same in calibration and validation data sets. Also, SSL lag 2 and 3 days autocorrelation coefficients are satisfactory. It is seen that the skewness coefficients are low in training and testing sets. It is noted that the high skewnees coefficient has a considerable negative effect on ANN 
Prediction of daily suspended sediment load

Table 1: Statistics analysis for training, testing and all data sets

\begin{tabular}{|c|c|c|c|c|c|c|}
\hline \multirow[b]{2}{*}{ Statistical parameters } & \multicolumn{2}{|c|}{ Training set } & \multicolumn{2}{|c|}{ Testing set } & \multicolumn{2}{|c|}{ All data set } \\
\hline & S (ton/day) & $\mathrm{Q}_{\left(m^{3} / \text { day }\right)}$ & S (ton/day) & $\mathrm{Q}_{\left(m^{3} / \text { day }\right)}$ & S (ton/day) & $\mathrm{Q}_{\left(m^{3} / \text { day }\right)}$ \\
\hline Mean & 1277.3 & $3.89 \times 10^{5}$ & 1475.8 & $5.07 \times 10^{5}$ & 1321.4 & $4.15 \times 10^{5}$ \\
\hline$S_{d}$ & 5026.9 & $8.02 \times 10^{5}$ & 4619.2 & $10.5 \times 10^{5}$ & 4939.2 & $8.65 \times 10^{5}$ \\
\hline Min & 0.009 & 1097.3 & 0.066 & 6359 & 0.009 & 1097.3 \\
\hline Max & 79315 & $149.47 \times 10^{5}$ & 42768 & $137.38 \times 10^{5}$ & 79315 & $149.47 \times 10^{5}$ \\
\hline$R_{1}$ & 0.676 & 0.809 & 0.861 & 0.865 & 0.712 & 0.828 \\
\hline$R_{3}$ & 0.288 & 0.529 & 0.576 & 0.487 & 0.344 & 0.517 \\
\hline
\end{tabular}

performance (Altun et al., 2007). In general, Table 1 shows satisfactory statistics characteristics between training and testing sets in terms of mean, standard deviation, skewness coefficient and correlation coefficient.

\section{Neuro-Fuzzy approach}

An special algorithm in neuro-fuzzy development is the adaptive neuro-fuzzy inference system (ANFIS). It is a network statement of Sugeno-type fuzzy models and is introduced by Jang (1993). The structure of an ANFIS is shown in Fig. 2. Fig. (2a) shows the fuzzy reasoning mechanism for the Sugeno model to derive an output function $f$ from a given input vector $[x, y]$.

The corresponding equivalent ANFIS construction is showed in Fig. (2b). As an example, a fuzzy inference system with two inputs $x$ and $y$ and one output $f$ was considered. For the first order Sugeno fuzzy model, a typical rule set with two fuzzy If-Then rules can be expressed as:

Rule 1: If $x$ is $A_{1}$ and $y$ is $B_{1}$, then $f_{1}=p_{1} x+q_{1} y+r_{1}$

Rule 2: If $x$ is $A_{2}$ and $y$ is $B_{2}$, then $f_{2}=p_{2} x+q_{2} y+r_{2}$

Where, $A_{1}, A_{2}$ and $B_{1}, B_{2}$ are the membership functions for inputs $x$ and $y$, respectively; $p_{1}, q_{1}, r_{1}$ and $p_{2}, q_{2}, r_{2}$ are the parameters of the output function. The functioning of the ANFIS is as follows:

Layer 1: The node output $O P_{i}^{l}$ is defined by:

$O P_{i}^{l}=\mu_{A i}(x)$ for $i=1,2$ or

$O P_{i}^{l}=\mu_{B i-2}(y)$ for $i=3,4$

Where, $x$ (or $y$ ) is the input to the node; $A_{i}\left(\right.$ or $\left.B_{i}-2\right)$ is a linguistic label (such as 'low' or 'high') associated with this node, characterized by the form of the membership functions in this node and can be any suitable functions that are continuous and piecewise differentiable such as Gaussian, trapezoidal shaped, generalized bell shaped and triangular shaped functions. The membership functions for $A$ and $B$ are usually described by generalized bell functions. The output $O P_{i}^{l}$ can be computed as:

$O P_{i}^{l}=\mu_{A i}(x)=\frac{1}{1+\left(\left(x-c_{i}\right) / a_{i}\right)^{2 b_{i}}}$

Where, $\left\{a_{i}, b_{i}, c_{i}\right\}$ is the parameter set.

Layer 2: Every node in this layer multiplies the incoming signals:

$O P_{i}^{2}=w_{i}=\mu_{A i}(x) \mu_{B i}(y), \quad, i=1,2$.

Layer 3: The ith node of this layer calculates the normalized firing strengths as:

$O P_{i}^{3}=\bar{w}_{i}=\frac{w_{i}}{w_{1}+w_{2}}, \quad i=1,2$.

Layer 4: Node $i$ in this layer calculates the contribution of the ith rule towards the model output:

$O P_{i}^{4}=\bar{w}_{i} f_{i}=\bar{w}_{i}\left(p_{i} x+q_{i} y+r_{i}\right)$

Where, $\bar{w}$ is the output of layer 3 and $\left\{p_{i}, q_{i}, r_{i}\right\}$ is the parameter set.

Layer 5: The single node in this layer calculates the overall output of the ANFIS as (Jang and Sun, 1995; Nayak et al., 2004; \$ Til et al., 2007):

$O P_{i}^{5}=\sum_{i} \bar{w}_{i} f_{i}=\frac{\sum_{i} w_{i} f_{i}}{\sum_{i} w_{i}}$

The optimization parameters in an ANFIS are the premise and consequent parameters. The learning algorithm is a hybrid algorithm, which is a 
combination of the gradient descent and least-squares approach. Firstly, in the forward pass of the learning technique, node outputs pass forward until layer (4) and the consequent parameters are established by the least-squares approach. In the backward pass, the error signals propagate backward and the premise parameters are updated by gradient descent. The consequent parameters thus identified are optimal under the condition that the premise parameters are fixed (Jang and Sun 1995; Aqil et al., 2007). A recommended literature for the NF model contains Jang and Mizutani (1996).

\section{Wavelet analysis}

The time-scale wavelet transform of a continuous time signal, $x(t)$, is defined as:

$$
T(a, b)=\frac{1}{\sqrt{a}} \int_{-\infty}^{+\infty} g^{*}\left(\frac{t-b}{a}\right) x(t) \cdot d t
$$

Where, * corresponds to the complex conjugate and $g(t)$ is called wavelet function or mother wavelet. The parameter $a$ acts as a dilation factor, while $b$ corresponds to a temporal translation of the function $g(t)$ (Mallat, 1998). The original signal may be reconstructed using the inverse wavelet transform as:

$$
x(t)=\frac{1}{c_{g}} \int_{-\infty}^{+\infty} \int_{0}^{\infty} \frac{1}{\sqrt{a}} a\left(\frac{t-b}{a}\right) T(a, b) \frac{d a \cdot d b}{a^{2}}
$$

A discretization of Eq.10 based on the trapezoidal rule maybe is the simplest discretization of the continuous wavelet transform. This transform produces $N^{2}$ coefficients from a data set of length $N$; hence redundant information is locked up within the coefficients, which may or may not be a desirable property (Addison et al., 2001). To overcome on the mentioned redundancy, logarithmic uniform spacing can be used for the $a$ scale discretization with correspondingly coarser resolution of the $b$ locations, which allows for $N$ transform coefficients to completely describe a signal of length $N$. Such a discrete wavelet is shown as follow:

$$
g_{m, n}(t)=\frac{1}{\sqrt{a_{0}^{m}}} g\left(\frac{t-n b_{0} a_{0}{ }^{m}}{a_{0}^{m}}\right)
$$

Where, $m$ and $n$ are integers; $b_{0}$ is the location parameter and $a_{0}$ is a specified fined dilation step. The most common choice for parameters are $a_{0}=2$ and $a_{0}=$
1. This power of two logarithmic scaling of the translation and dilation is known as the dyadic grid arrangement (Szilagyi et al., 1996). The dyadic wavelet can be written in more compact notation as:

$g_{m, n}(t)=2^{-m / 2} g\left(2^{-m} t-n\right)$

For a discrete time series, $\mathrm{x}_{i}$, the dyadic wavelet transform becomes:

$T_{m, n}=2^{-m / 2} \sum_{i=0}^{N-1} g\left(2^{-m} i-n\right) x_{i}$

Where, $T_{m, n}$ is wavelet coefficient for the discrete wavelet of scale $a=2^{m}$ and location $b=2^{m} n$. Eq. 14 considers a finite time series, $x_{i}, i=0,1,2, \ldots, N-1$ and $N$ is an integer power of 2: $N=2^{M}$. This gives the ranges of $m$ and $n$ as respectively, $0<n<2^{M-m}-1$ and $1<m<M$. At the largest wavelet scale (i.e., $2^{\mathrm{m}}$ where $m=M$ ) just one wavelet is needed to cover the time interval and only one coefficient is created. At the next scale $\left(2^{m-1}\right)$, two wavelets cover the time interval, therefore two coefficients are created and so on down to $m=1$. At $m=1$, the $a$ scale is $2^{1}$, i.e. $2^{\mathrm{M}-1}$ or $\frac{N}{2}$ coefficients are needed to describe the signal at this scale. The total number of wavelet coefficients for a discrete time series of length $N=2^{M}$ is then $1+2+4+8+\ldots+2^{M-1}=N-1$ (Addison et al., 2001).

A signal smoothed component, $\bar{T}$, is left, which is the signal mean. Therefore a time series of length $N$ is broken into $N$ components, i.e., with zero redundancy. The inverse discrete transform is given by:

$x_{i}=\bar{T}+\sum_{m=1}^{M} \sum_{n=0}^{2^{M-m}-1} T_{m, n} 2^{-m / 2} g\left(2^{-m} i-n\right)$

or in a simple format as:

$x_{i}=\bar{T}(t)+\sum_{m=1}^{M} W_{m}(t)$

Where, $\bar{T}(t)$ is called approximation sub-signal at level $M$ and $W_{m}(t)$ are details sub-signals at levels $m=1,2, \ldots, M$. The wavelet coefficients, $W_{m}(t)$, $m=, 1,2, \ldots, M$, provide the detail signals, which can capture small features of interpretational value in the data; the residual term, $\bar{T}(t)$, represents the background information of data. Because of simplicity of $W_{1}(t), W_{2}(t), \ldots, W_{M}(t), \bar{T}(t)$, some exciting properties 
can be determine easily by means these components. Recommended literatures for the wavelet beginner contain Mallat (1998) and Labat et al. (2000).

\section{Proposed Wavelet-Neuro-Fuzzy model}

To construct the model, firstly measured river discharge and SSL time series were decomposed to some multi-frequently time series $Q_{d 1}(t), Q_{d 2}(t), \ldots, Q_{d i}(t)$,
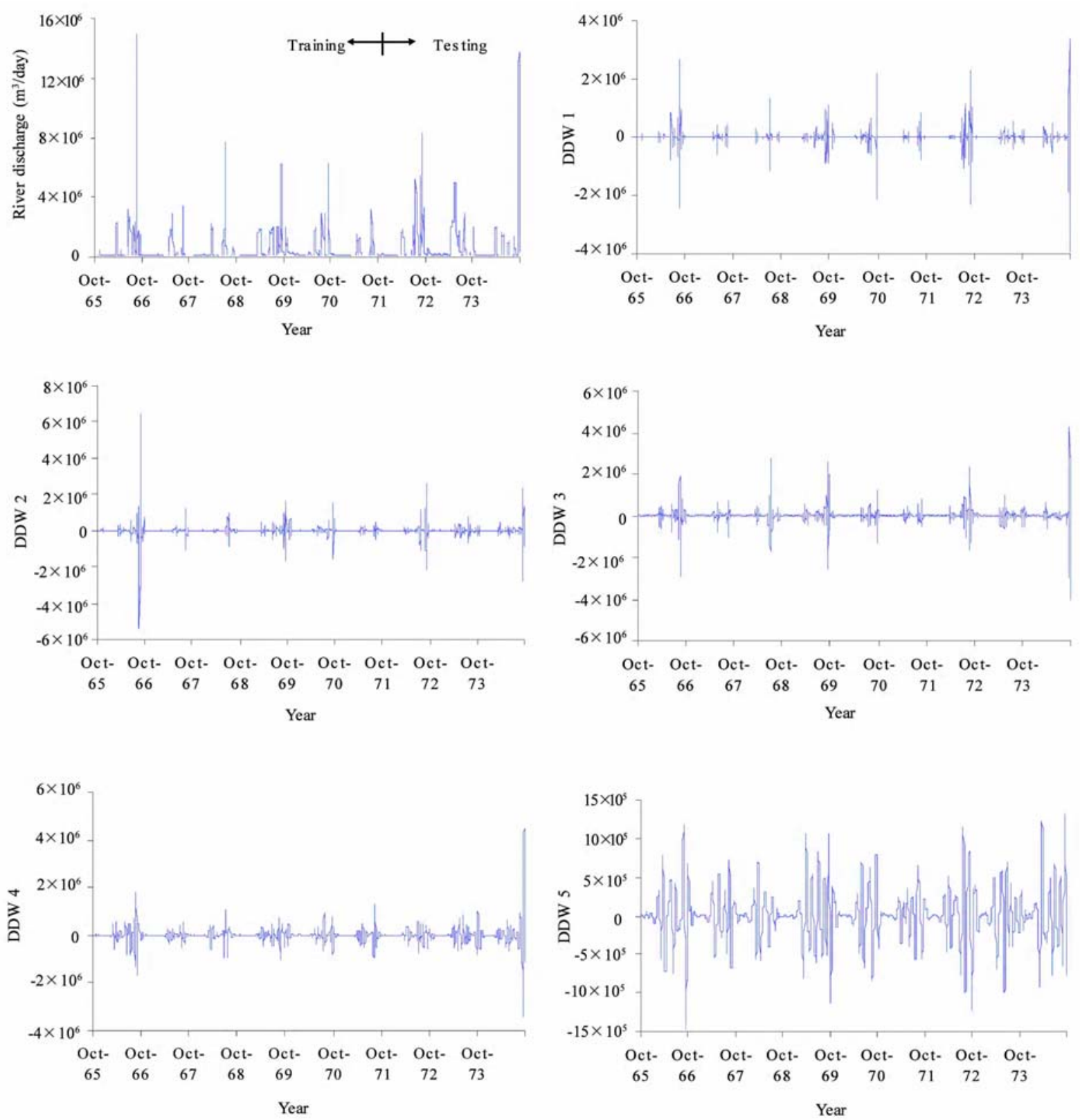

Fig. 3: Observed and decomposed river discharge sub-time series

$Q_{a}(t)$ and $S_{d 1}(t), S_{d 2}(t), \ldots, S_{d i}(t), S_{a}(t)$ by discrete wavelet transform (DWT). Which $Q_{d 1}(t), Q_{d 2}(t), \ldots, Q_{d i}(t)$ and $Q_{a}(t)$ are the details and approximation (or background) river discharge time series, respectively; $S_{d 1}(t), S_{d 2}(t), \ldots, S_{d i}(t)$ and $S_{a}(t)$ are the details and approximation SSL time series, respectively; di shows the level $i$ decomposed time series and $a$ denotes
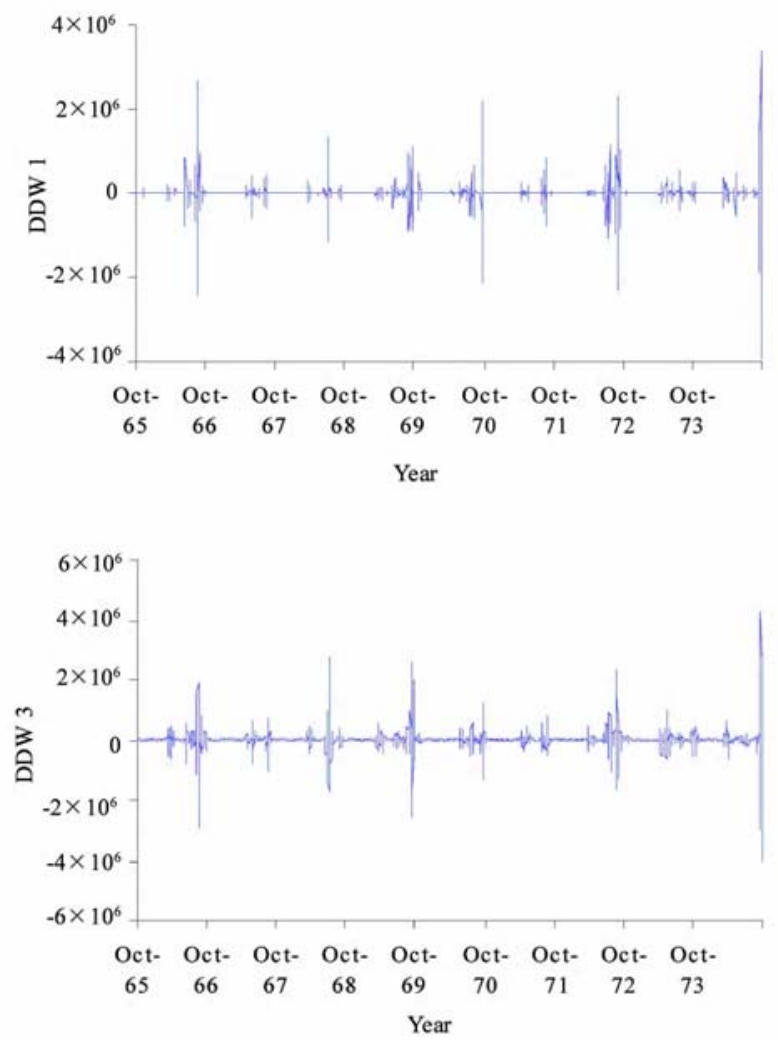

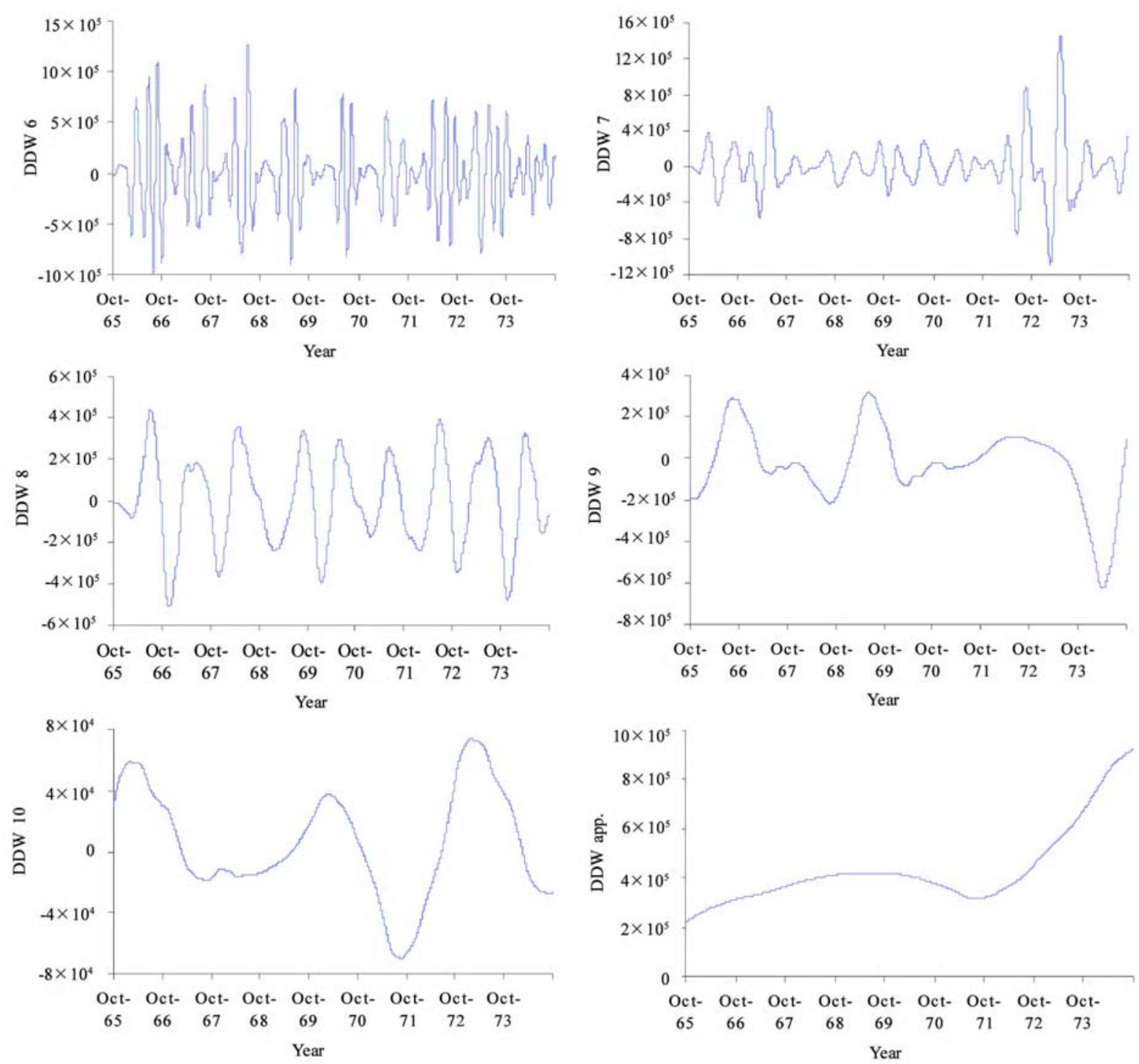

Fig. 3 (continued): Observed and decomposed river discharge sub-time series

Table 2: The correlation coefficients of the discrete wavelet components with the measured SSL $\left(S_{t}\right)$

\begin{tabular}{|c|c|c|c|c|c|}
\hline $\begin{array}{l}\text { Discharge discrete } \\
\text { wavelet components }\end{array}$ & $\begin{array}{l}\text { Correlation between } \\
D D W(i)_{t-1} \text { and } S_{t}\end{array}$ & $\begin{array}{l}\text { Correlation between } \\
D D W(i)_{t-2} \text { and } S_{t}\end{array}$ & $\begin{array}{l}\text { SSL discrete wavelet } \\
\text { components }\end{array}$ & $\begin{array}{l}\text { Correlation between } \\
S D W(i)_{t-1} \text { and } S_{t}\end{array}$ & $\begin{array}{l}\text { Correlation between } \\
S D W(i)_{t-2} \text { and } S_{t}\end{array}$ \\
\hline DDW 1 & -0.087 & -0.043 & SDW 1 & -0.144 & -0.038 \\
\hline DDW 2 & 0.054 & -0.233 & SDW 2 & 0.13 & -0.218 \\
\hline DDW 3 & 0.32 & 0.124 & SDW 3 & 0.381 & 0.152 \\
\hline DDW 4 & 0.25 & 0.191 & SDW 4 & 0.330 & 0.278 \\
\hline DDW 5 & 0.293 & 0.279 & SDW 5 & 0.387 & 0.387 \\
\hline DDW 6 & 0.248 & 0.236 & SDW 6 & 0.273 & 0.258 \\
\hline DDW 7 & 0.282 & 0.282 & SDW 7 & 0.305 & 0.305 \\
\hline DDW 8 & 0.2198 & 0.221 & SDW 8 & 0.249 & 0.249 \\
\hline DDW 9 & 0.1126 & 0.1124 & SDW 9 & 0.121 & 0.121 \\
\hline DDW 10 & 0.0855 & 0.0852 & SDW 10 & 0.105 & 0.105 \\
\hline DDW App. & 0.03 & 0.0296 & SDW App. & 0.059 & 0.058 \\
\hline
\end{tabular}




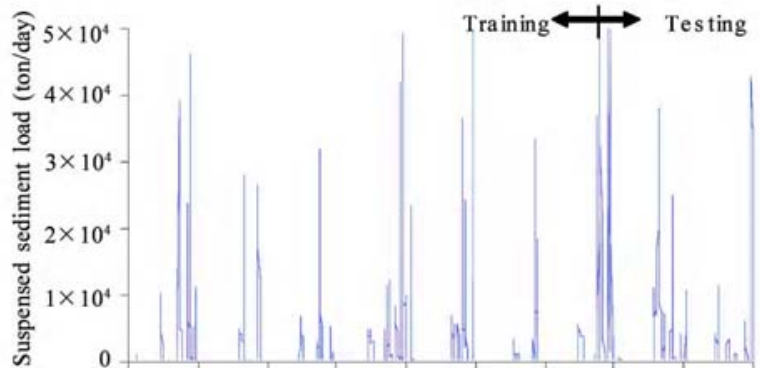

Oct- Oct- Oct- Oct- Oct- Oct- Oct- Oct- Oct$\begin{array}{lllllllll}65 & 66 & 67 & 68 & 69 & 70 & 71 & 72 & 73\end{array}$

Year

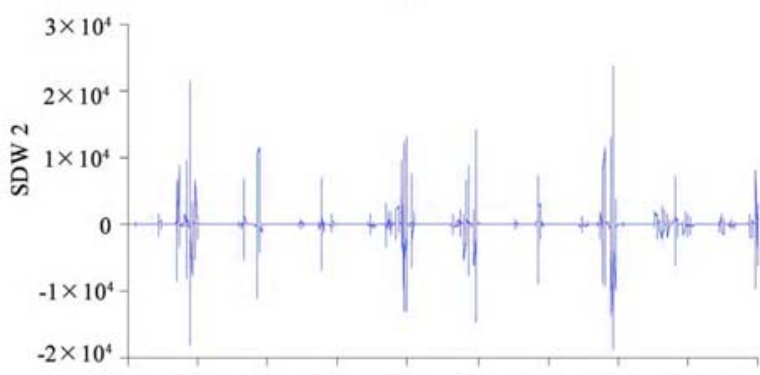

Oct- Oct- Oct- Oct- Oct- Oct- Oct- Oct- Oct$\begin{array}{lllllllll}65 & 66 & 67 & 68 & 69 & 70 & 71 & 72 & 73\end{array}$

Year
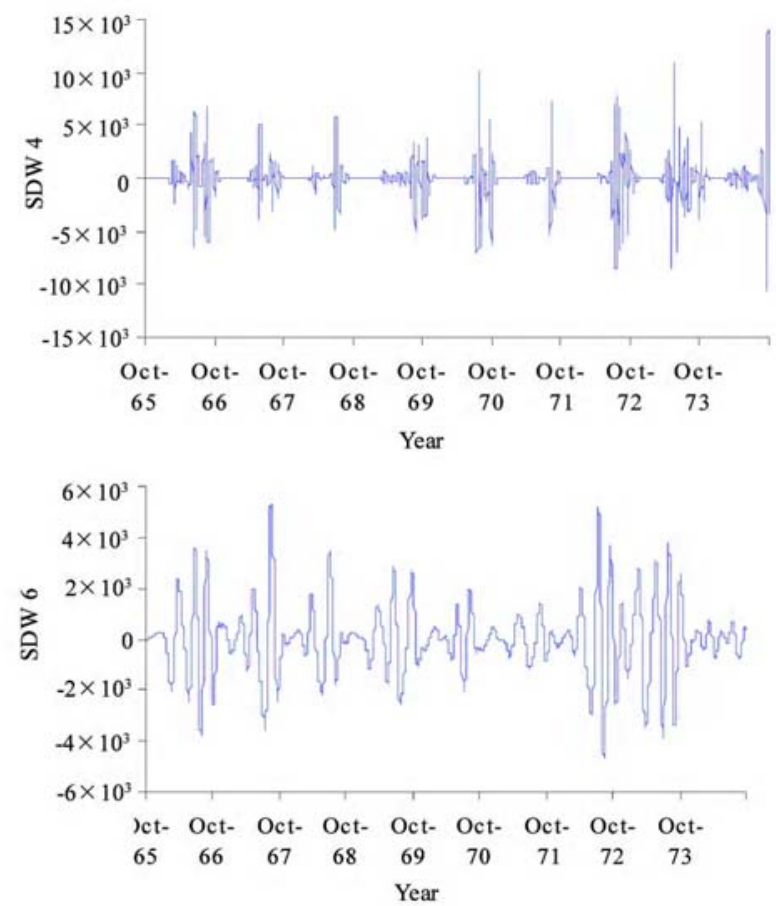
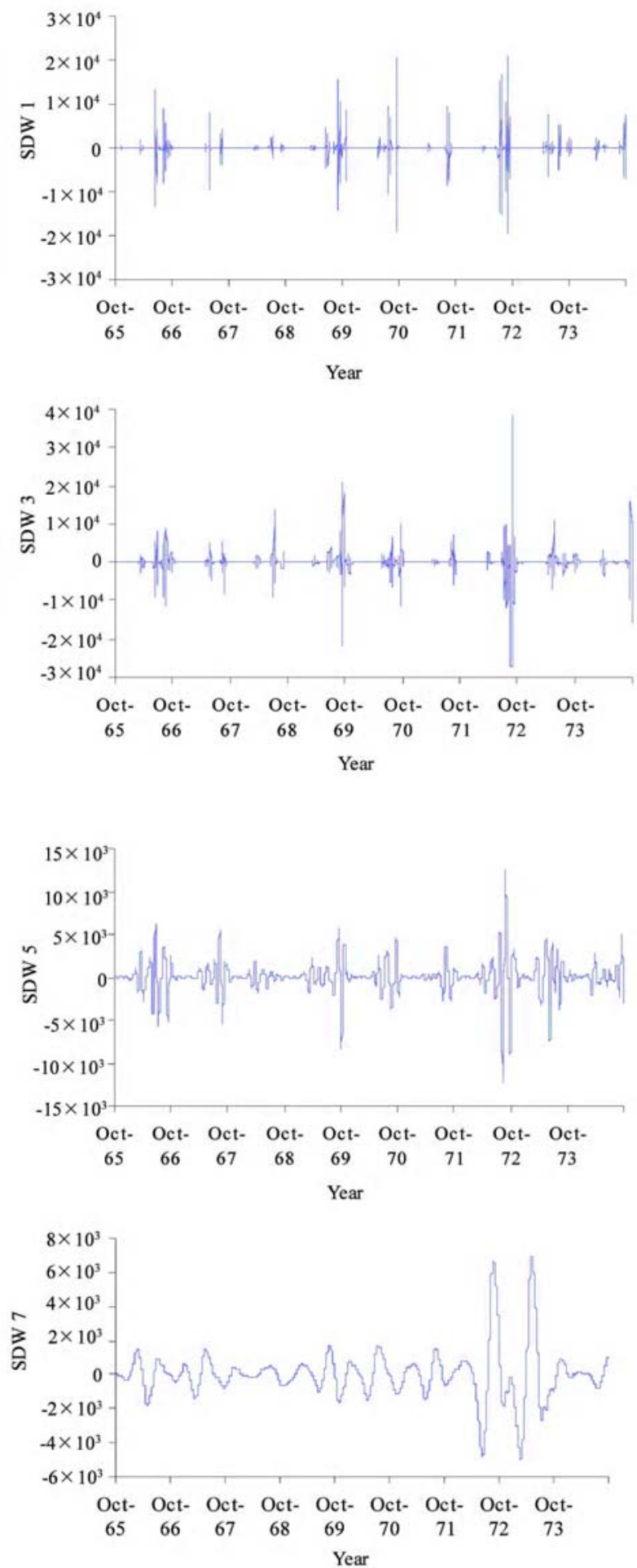

Fig. 4: Observed and decomposed SSL sub-time series 

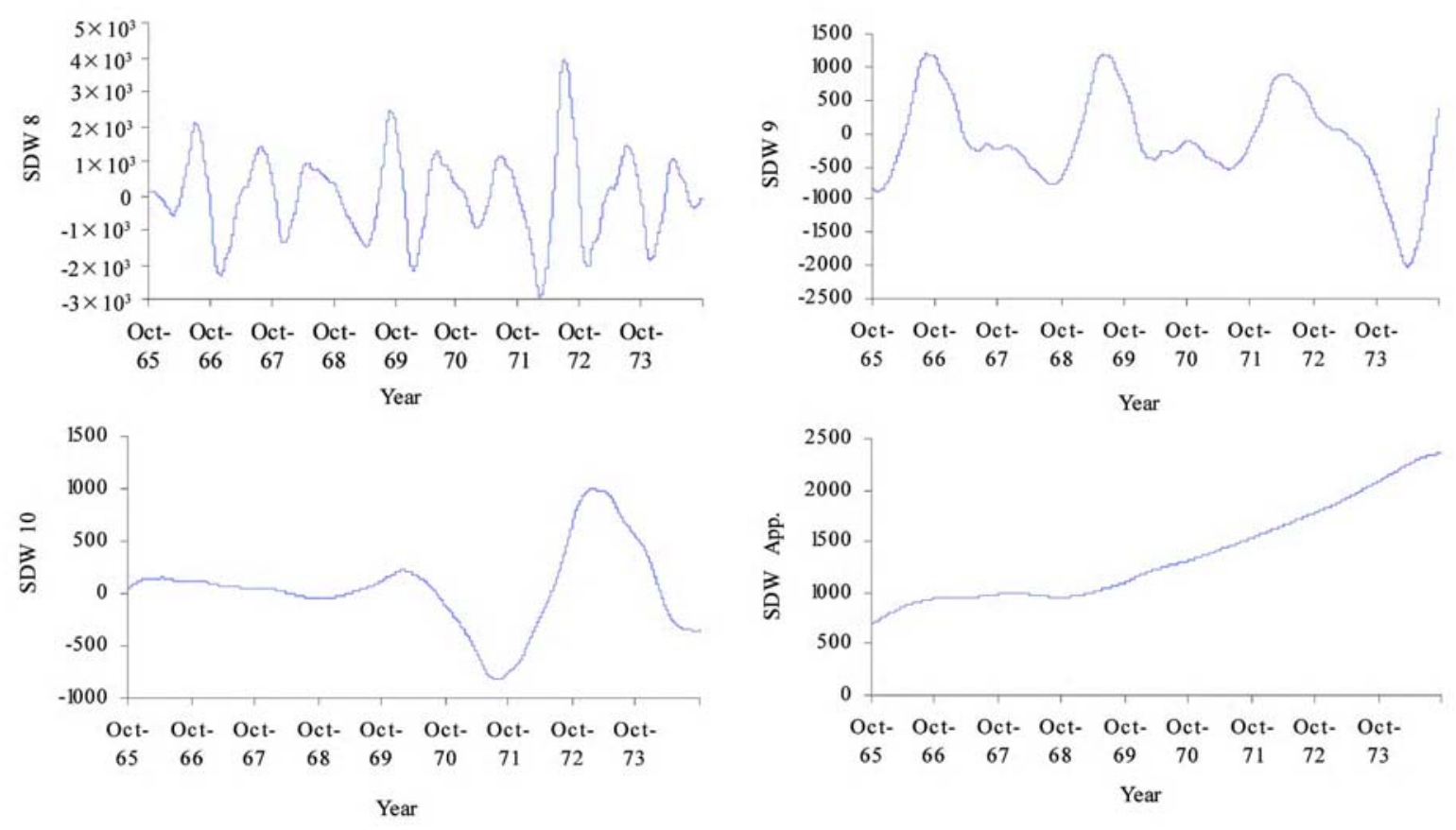

Fig. 4 (continued): Observed and decomposed SSL sub-time series

approximation time series. These time series play various roles in the original time series and the behavior of each is distinct. The measured river flow and SSL time series was decomposed using different scales, from 1 to 10 (i.e. into 10 wavelet decomposition levels (2-4-8-16-32-64-128-256-512-1024 days). The river discharge time series of 2-day mode (DDW 1), 4day mode (DDW 2), 8-day mode (DDW 3), 16-day mode (DDW 4), 32-day mode (DDW 5), 64-day mode (DDW 6), 128-day mode (DDW 7), 256-day mode (DDW 8), 512-day mode (DDW 9), 1024-day mode (DDW 10) and approximate mode (DDW App.) are shown in Fig. 3. Also, the decomposed SSL time series (SDW) of the mentioned modes are illustrated in Fig. 4. The discrete wavelet transform belongs to the multi resolution analysis (Mallat, 1989; Daubechies, 1990). It decomposes the time series into a set of basis functions of various frequencies. In this study, the river discharge and SSL time series are constructed by a very irregular signal form. Therefore, an irregular wavelet, the Daubechies wavelet of order 4 (db4) (Daubechies, 1992), was selected for employing in this paper. The aim of this research is to substitute the prediction of the observed SSL of high variability by the prediction of its summed wavelet coefficients on various levels of reduced variabilities. Remaining issues contain determining which wavelet levels are most effective in SSL prediction. In this part, in order to select the forceful wavelet components in prediction, the correlation coefficients between decomposed river discharge and SSL with original SSL time series are calculated and illustrated in Table 2. Since majority of the decomposed time series are of lower variability prepared for the increase of the prediction precision.

According to the Table 2, DDW 1, DDW 2, DDW 9 , DDW 10 and DDW App. show low correlation with original SSL, therefore DDW 3, DDW 4, DDW 5, DDW 6, DDW 7 and DDW 8, were selected as effective wavelet components and were summed together to obtain total discharge discrete wavelet (TDDW). In this manner, SDW 1, SDW 2, SDW 10 and SDW App. show low correlation with original SSL, thus SDW 3, SDW 4, SDW 5, SDW 6, DDW 7, DDW 8 and SDW 9 which have high correlation, were chosen as forceful wavelet components and summed together to provide total sediment discrete wavelet (TSDW). In Fig. 5, the TDDW and TSDW are shown.

The correlation coefficients between discharge, TDDW and TSDW with original SSL $\left(S_{t}\right)$ to have first 

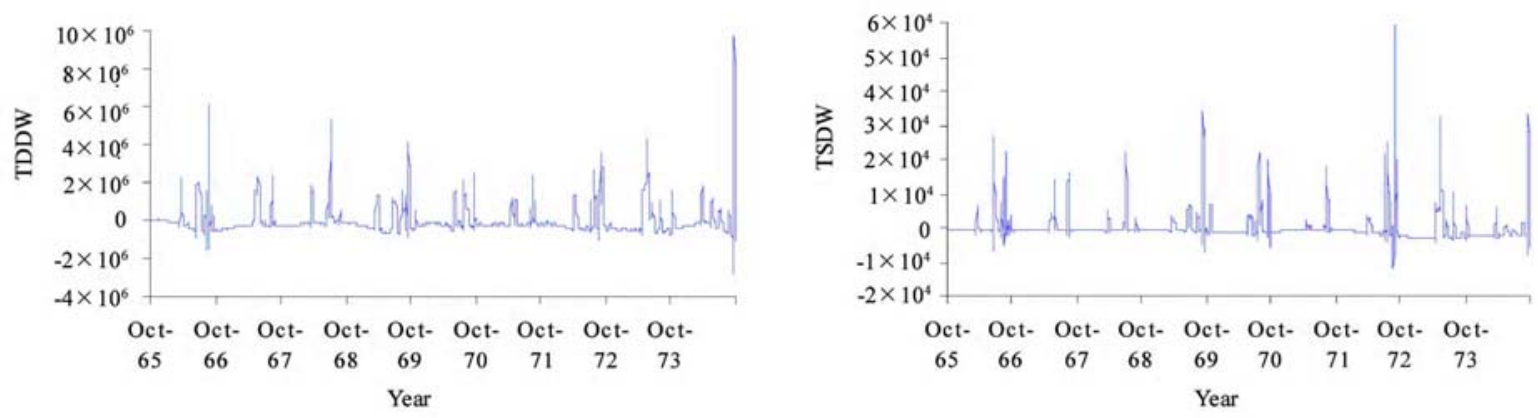

Fig. 5: TDDW and TSDW time series

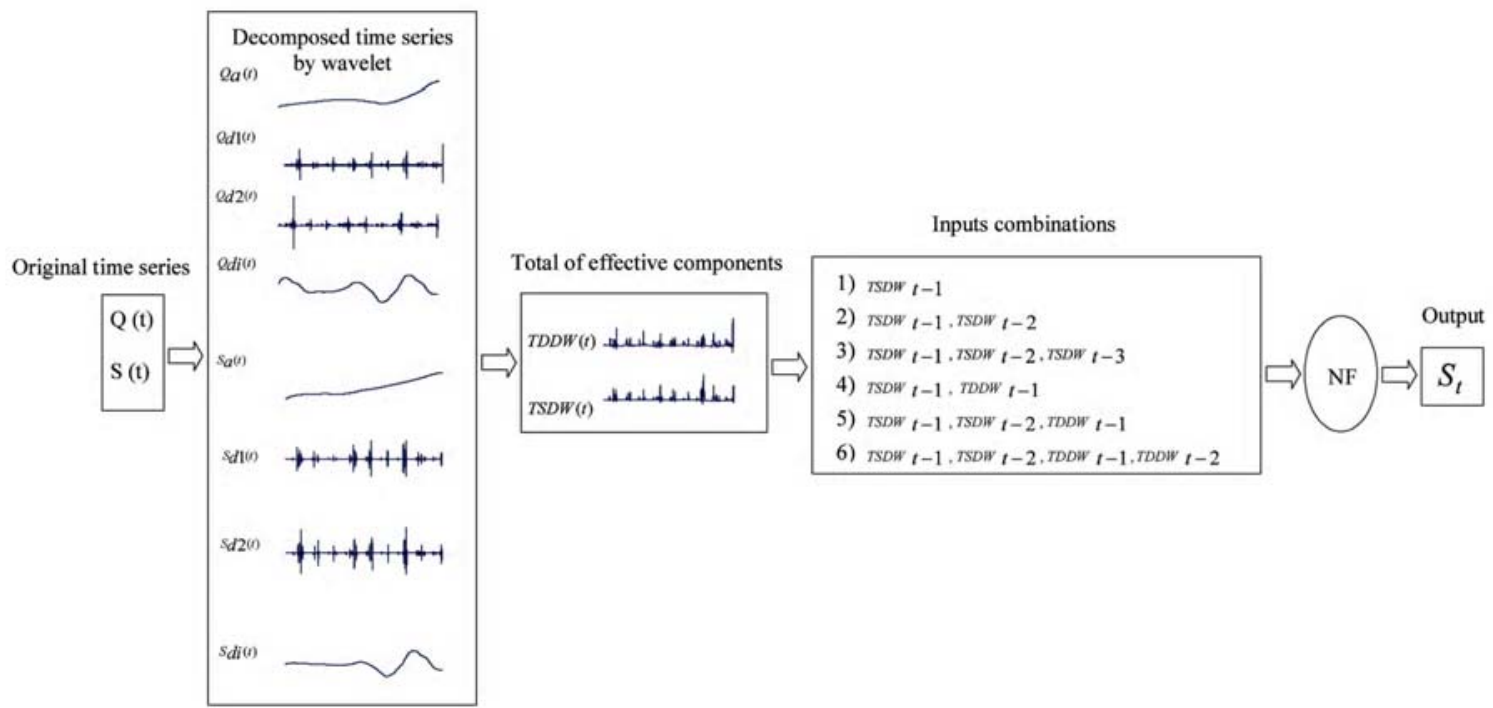

Fig. 6: Construction of the proposed WNF model

hand knowledge about the suitability of NF and WNF models input construction are calculated and shown in Table 3. According to Table 3, correlation coefficient between SSL $\left(S_{t}\right)$ and $Q_{t-1}$ is 0.616 , while it is 0.654 for $T D D W_{t-1}$ and correlation coefficient between SSL and $Q_{t-2}$ is 0.424 , but it is 0.537 for $T D D W_{t-2}$. Also, SSL lag 1 day autocorrelation coefficient is 0.712 (Table 1 ), while it is 0.8 for $T S D W_{t-1}$ and SSL lag 2 days autocorrelation coefficient is 0.48 , but it is 0.648 for $T S D W_{t-2}$. It is obvious that the wavelet analysis is extremely useful when employed before correlation coefficient assessment to extract effective sub-time series in SSL prediction. In Fig. 6 the construction of the proposed WNF model is shown. Wavelet transforms provide useful decompositions of main time series, so that wavelet-transformed data improve the ability of a predicting model by capturing useful information on various resolution levels. Hence a hybrid WNF model which uses summed multi-scale signals as input data may present more probable prediction rather than a single pattern input.

\section{Sediment rating curve (SRC) method}

In many rivers a main part of the sediment is transported in suspension. Almost of this load contained of silt and clay, i.e. wash load. Thus, it can be concluded that wash load plays an important role in the sediment transport in rivers (Asselman, 2000). The primary data collected to determine the suspended sediment discharge of a river are $Q_{w}$ and C. $Q_{w}\left(\mathrm{~m}^{3} / \mathrm{s}\right)$ 
is the instantaneous river discharge and measured with a current meter or taken from a stage-discharge curve for the gauging station. $C$ is the instantaneous suspended sediment concentration in $\mathrm{mg} / \mathrm{L}$ or $\mathrm{ppm}$. Concentration is measured by analysis of water samples. Finally, the instantaneous suspended sediment discharge (ton/day) is calculated from $Q_{w}$ and $C$. As the finest fraction of the SSL often is a non-capacity load, it cannot be predicted using stream power related sediment transport models. Instead, empirical relations such as sediment rating curves often are applied (Asselman, 2000). The establishment of a SRC is an important object of hydrology. Since the measurement of sediment is costly and time-consuming, usually discharge is measured per day. The SRC is used to assess the sediment discharge corresponding to the measured flow discharge. Usually, the SRC has the form $S=a Q_{w}^{b}$ where $S$ is the suspended sediment load or discharge and $a$ and $b$ are constants. Thus, the SRC has important bearing on correct assessment of SSL. As a SRC can be considered a 'black box' type of model, the coefficients $a$ and $b$, have no physical meaning. However, some physical interpretation is often ascribed to them. The $a$ coefficient shows an index of erosion severity. High $a-$ values demonstrate intensively basin materials. The $b$ coefficient shows the erosive power of the stream, with large values being indicative for streams where a small increase in river discharge results in a strong increase in erosive power of the stream (Sarma, 1986; Morgan, 1995).

\section{RESULTS AND DISCUSSION}

Application of NF, WNF and SRC models

The performance of NF, WNF and SRC models in prediction of SSL in one day ahead is the subject of this research. Time series simulation is fundamentally various from the conceptual simulation and modeling of systems in several aspects. Although, a time series can be interpreted as an output of a system, it is, by definition, an output of an unknown system (Lopez et al., 1996). With respect to statistics analysis in Tables 1 and 3 , the following combinations that contain various values of river discharge and SSL are regarded in the input layer to predict the single SSL in one day ahead at time $t\left(S_{t}\right)$ in the output layer for NF model.
1) $S_{t-1}$
4) $Q_{t-1}, S_{t-1}$
2) $S_{t-1}, S_{t-2}$
5) $Q_{t-1}, S_{t-1}, S_{t-2}$
3) $S_{t-1}, S_{t-2}, S_{t-3}$
6) $Q_{t-1}, Q_{t-2}, S_{t-1}, S_{t-2}$

Table 3: The correlation coefficients between discharge, TDDW and TSDW with observed SSL (St)

\begin{tabular}{lc}
\hline Time series & Correlation coefficient with $\mathrm{S}_{\mathrm{t}}$ \\
\hline$Q_{t}$ & 0.819 \\
$Q_{t-1}$ & 0.616 \\
$Q_{t-2}$ & 0.424 \\
$T D D W_{t}$ & 0.712 \\
$T D D W_{t-1}$ & 0.654 \\
$T D D W_{t-2}$ & 0.537 \\
$T S D W_{t}$ & 0.863 \\
$T S D W_{t}$ & 0.8 \\
$T S D W_{t}$ & 0.648 \\
\hline
\end{tabular}

The provided NF model in this study used a fuzzy inference algorithm of Sugeno type, in which the membership function parameters were achieved to fit a given input-output set by the hybrid optimization algorithm. In this model, each rule includes some parameters of membership functions (MFs) and each variable may have some values (in terms of rules). For instance, if each variable has two rules and each rule includes three parameters, then there are $6 n$ [n (variables) $\times 2$ (rules) $\times 3$ (parameters)] parameters for the distinction in layer 1 in Fig. 2. The model calibrates these MFs in relation to training data. These rules create $2^{n}$ nodes in layer 3 . Taking the number of MFs for each input expresses the complexity of NF technique for stating parameters. The most important benefit of the neuro-fuzzy over traditional models is that it does not need an explicit relation of the complicated nature of the underlying process in a mathematical scheme. It is essential that the construction of the model matches the data. In this paper, the structures of the NF models are determined employing a trial and error approach to produce the best NF construction. Model performance was examined for each input combination (1-6) for the number of MFs varying from 2 to 4.

In the current study, the Gaussian membership function has been used, because the most common approach to neuro-fuzzy model is to use the Gaussian membership function (Jaradat et al., 2008; Chuang et al., 2009). Also, in a fuzzy system having Gussuian membership functions, product inference rule and weighted average defuzzifier is constructed and has become the standard method in most application (Wang, 1994). Comparing the Gaussian, triangular and trapezoidal membership functions have been showed that triangular and trapezoidal membership functions boundary are straight lines, which cause the response 
difference quite a lot in the boundary. As for Gaussian membership function hypothesis, because, is curve boundary situation compared to the triangular and trapezoidal thus improved the model efficiency (Chang and Lin, 2007; Hidalgo et al., 2009). According to Fig. 6, in WNF model the total decomposed time series were entered to the NF model for prediction of SSL in one day ahead. The aim of discrete wavelet analysis is to decompose observed time series into a finite summation of wavelets at various levels of expansion. In WNF model, the following combinations that include different values of TSDW and TDDW are considered in the input layer to predict the single SSL in one day ahead at time $t$ in the output layer.

1) $T S D W_{t-1}$

2) $T S D W_{t-1}, T S D W_{t-2}$

4) $T S D W_{t-1}, T D D W_{t-1}$

3) $T S D W_{t-1}, T S D W_{t-2}, T S D W_{t-3}$

5) $T S D W_{t-1}, T S D W_{t-2}, T D D W_{t-1}$

6) $T S D W_{t-1}, T S D W_{t-2}, T D D W_{t-1}, T D D W_{t-2}$

Also, the sediment rating curve was fitted to the calibration data and equation 17 was obtained.

$S=8 \times 10^{-9} Q^{1.7975}$

Then, the predictive capability of the SRC model was tested with the testing data set.

\section{Performance evaluation}

Some conventional performance evaluations such as correlation coefficient (R), coefficient of determination, root mean square error (RMSE) and sum of square error (SSE) and so on, were reviewed by Legates and McCabe (1999). The authors illustrated that the correlation coefficient is unsuitable for model evaluation. They indicated a perfect evaluation of model performance should include at least one 'goodness-of-fit' or relative error measure (e.g. ) and at least one absolute error measure (e.g., RMSE or mean absolute error (MAE)). Nash and Sutcliffe (1970) described which ranges from minus infinity to 1.0 , with higher values describing better agreement. Also, this method of evaluation was used by Nourani et al., (2009). In this study, SSE and RMSE were calculated for various predictions by utilized models. SSE computes the sum of square difference between measured and predicted SSL, RMSE calculates residual between actual and predicted SSL and clarifies the relation between original and predicted values
(Appendix). The best model was selected based on the highest and lowest SSE or RMSE.

\section{Models evaluation}

NF, WNF and SRC models were employed in the time series simulation of SSL for all input combinations and the results are shown by Table 4 .

According to the Table 4, in various structures of the NF model, combination 3 is the best model that uses $S_{t-1}, S_{t-2}, S_{t-3}$ as inputs and four Gaussian membership functions. Also, in WNF model, combination 2 that employs TSDW $W_{t-1}, T S D W_{t-2}$ as NF model inputs shows the best result. In sediment-river discharge relationship, it is established that sediment is the output and river discharge is one of the inputs. This is also validated from the SRC approach provided for the station. Combinations 1 and 2 are similar to combinations 4 and 5, respectively, except for the river discharge term $\left(Q_{t-1}\right)$. In NF model, the input combination 4 suitably executes in contrast of the combination 1. Besides, the combination 5 satisfactory performs as compared to the combination 2. The WNF model prepares similar results just for input combinations 1 and 4 . For NF models, insertion of $Q_{t-2}$ to the combination 5 increased the model performance (combination 6). The results obtained by NF models illustrate that the inclusion of $Q_{t-1}$ and $Q_{t-2}$ in the model inputs agreement influences to the models performance. The cross-correlations computed between discharge and SSL in Table 3 express the relation between river flow and SSL time series and confirm the results. The amount of $R^{2}$, SSE and RMSE for NF models are in the ranges of 0.622-0.67, $4.72 \times 10^{9}-5.88 \times 10^{9}$ and 2543-2837.7, respectively, whereas the mentioned statistical parameters are in the ranges of $0.716-0.867,2.07 \times 10^{9}-4.42 \times 10^{9}$ and 1685.6-2459.6, respectively for the WNF models and they are $0.44,8.78 \times 10^{9}$ and 3467.1 , respectively, for SRC approach. Results reveal that the WNF models which use sum of effective decomposed data (with high correlation coefficient) have shown better performance than NF models which use row data (with low correlation coefficient). In WNF model by selecting different decomposition levels for each variable, it may be considered many different levels including long, intermediate and short levels. According to the Table 4, 
Int. J. Environ. Sci. Tech., 7 (1), 93-110, Winter 2010

Table 4: $R^{2}$ SSE and RMSE in SSL prediction by NF, WNF and SRC models for testing period

\begin{tabular}{|c|c|c|c|c|c|c|c|c|c|c|c|c|c|}
\hline Models & & & & NF & & & & & & NF & & & SRC \\
\hline Combination & 1 & $2^{*}$ & 3 & 4 & 5 & 6 & 1 & 2 & $3^{*}$ & 4 & 5 & 6 & - \\
\hline MF number & 4 & 4 & 4 & 4 & 4 & 4 & 4 & 4 & 4 & 4 & 4 & 4 & - \\
\hline $\begin{array}{l}R^{2} \\
\mathrm{SSE} \times 10^{9}\end{array}$ & 0.796 & 0.867 & 0.847 & 0.806 & 0.843 & 0.716 & 0.622 & 0.642 & 0.67 & 0.645 & 0.659 & 0.665 & 0.44 \\
\hline $\begin{array}{l}\text { (ton/day) }{ }^{2} \\
\text { RMSE }\end{array}$ & 3.17 & 2.07 & 2.38 & 3.01 & 2.44 & 4.42 & 5.88 & 5.56 & 4.72 & 5.52 & 4.97 & 4.88 & 8.78 \\
\hline (ton/day) & 2082.8 & 1685.6 & 1805.3 & 2030.9 & 1828.2 & 2459.6 & 2837.7 & 2760.5 & 2543 & 2750.5 & 2608.7 & 2585.2 & 3467.1 \\
\hline
\end{tabular}

Table 5: Utilized models in SSL prediction in verification period for values greater than 12000 (ton/day)

\begin{tabular}{|c|c|c|c|c|c|}
\hline Row & Date & Observed (ton/day) & NF (ton/day) & WNF (ton/day) & SRC (ton/day) \\
\hline 1 & 23-Sep-74 & 42768 & 28329 & 35561 & 48752.6 \\
\hline 2 & 22-Sep-74 & 39053.7 & 808.96 & 20345 & 15503 \\
\hline 3 & 20-May-73 & 38029.8 & 21920 & 28780 & 7361.6 \\
\hline 4 & 17-May-73 & 36661.3 & 13905 & 21149 & 7874.3 \\
\hline 5 & 18-May-73 & 34100.4 & 25302 & 25619 & 8617.7 \\
\hline 6 & 19-May-73 & 32864.8 & 22081 & 30636 & 8617.7 \\
\hline 7 & 24-Sep-74 & 32558.1 & 27402 & 32022 & 54135.8 \\
\hline 8 & 27-Jul-73 & 24952.8 & 3965.9 & 11154 & 3436.9 \\
\hline 9 & 22-May-73 & 20418.7 & 11731 & 17487 & 3957.5 \\
\hline 10 & 16-May-73 & 20120.4 & 11529 & 17882 & 4633.1 \\
\hline 11 & 21-May-73 & 19091.6 & 25604 & 23156 & 4449.7 \\
\hline 12 & 23-May-73 & 18657.2 & 14540 & 7980.3 & 3637.5 \\
\hline 13 & 15-May-73 & 16916.9 & 11679 & 14790 & 3329.6 \\
\hline 14 & 14-May-73 & 16455.1 & 7856.6 & 11503 & 3637.5 \\
\hline 15 & 01-Aug-73 & 16039.3 & 5023.2 & 8031.9 & 1781.8 \\
\hline 16 & 28-Jul-73 & 15545.8 & 18057 & 10274 & 1781.8 \\
\hline 17 & 28-May-73 & 12026.9 & 8342.7 & 8087.7 & 3527.5 \\
\hline$R^{2}$ & & & -1.21 & 0.21 & -2.91 \\
\hline SSE $\times 10^{9}(\text { ton} / \text { day })^{2}$ & & & 3.56 & 1.28 & 6.29 \\
\hline RMSE (ton/day) & & & 14472.1 & 8664.8 & 19235.6 \\
\hline
\end{tabular}

the proposed WNF model was able to improve the SSE and RMSE values of NF model by about $56.14 \%$ and $33.72 \%$, respectively. Also, the WNF was able to improve the mentioned parameters for SRC method by about 76.42 $\%$ and $51.38 \%$, respectively. According to the mean and variance values of the SSL (Table 1), it is obvious that the river discharge, sediment yield budget and their variations in Pecos River station are sensible. Therefore, it is expected that the performance of WNF model (because of its capability) would be more accurate than the NF and SRC models. Due to the inherent nonlinearity and complexity of the SSC phenomenon, linear model (i.e. SRC) does not show considerable efficiency. The SRC model tends to under-predict high and over-predict low SSL; as there are relatively only a few highs (storm events) compared with a large number of lows (base flow) in the data set. For support the all above results by visual inspection, the time series of measured and predicted SSL employing NF, WNF and SRC models for verification period are plotted in Figs. 7 to 9. Furthermore, the scatter plot of SSL predictions by the models were plotted against observed SSL. The both NF and WNF models underestimate the peaks, but WNF predictions are closer to the high SSL values than the NF predictions. It is seen that the WNF model gives better performance than NF approach for prediction of low, medium and high SSL values in all testing period. It can be seen that the WNF predictions is closer to $45^{\circ}$ straight line than NF predictions in all testing domains. SRC approach employs all river discharge and SSL calibration data as a regression method, while in training set, most river discharge and SSL values are low; hence, this model underestimates the SSL values for validation period. As it is raised from Figs. 3 and 4, the observed discharge and SSL are varying during the periods of this research. The number of patterns, including high values of river flow and especially SSL is sufficiently less than the number of patterns including low and medium values of discharge and SSL for calibration period. Thus, the predicted SSL based on the calibration set have a bias towards the low and medium SSL in NF and WNF models. 

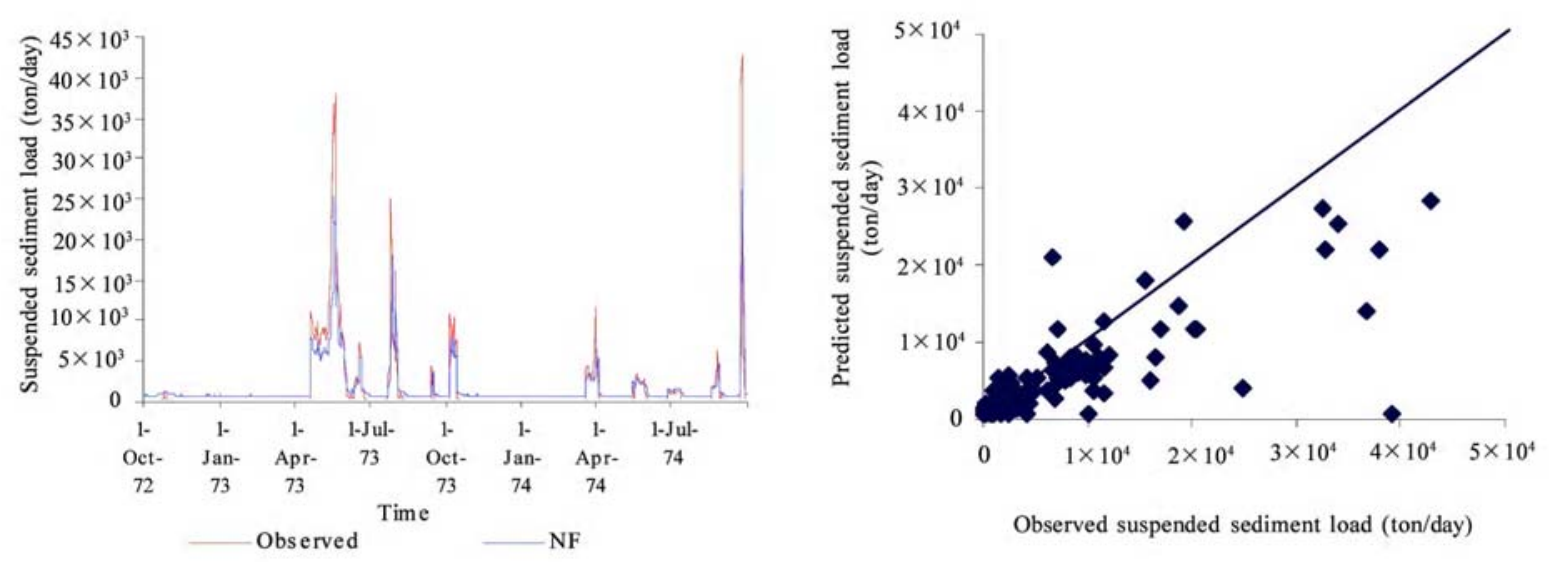

Fig. 7: Observed and predicted SSL using NF model in verification period
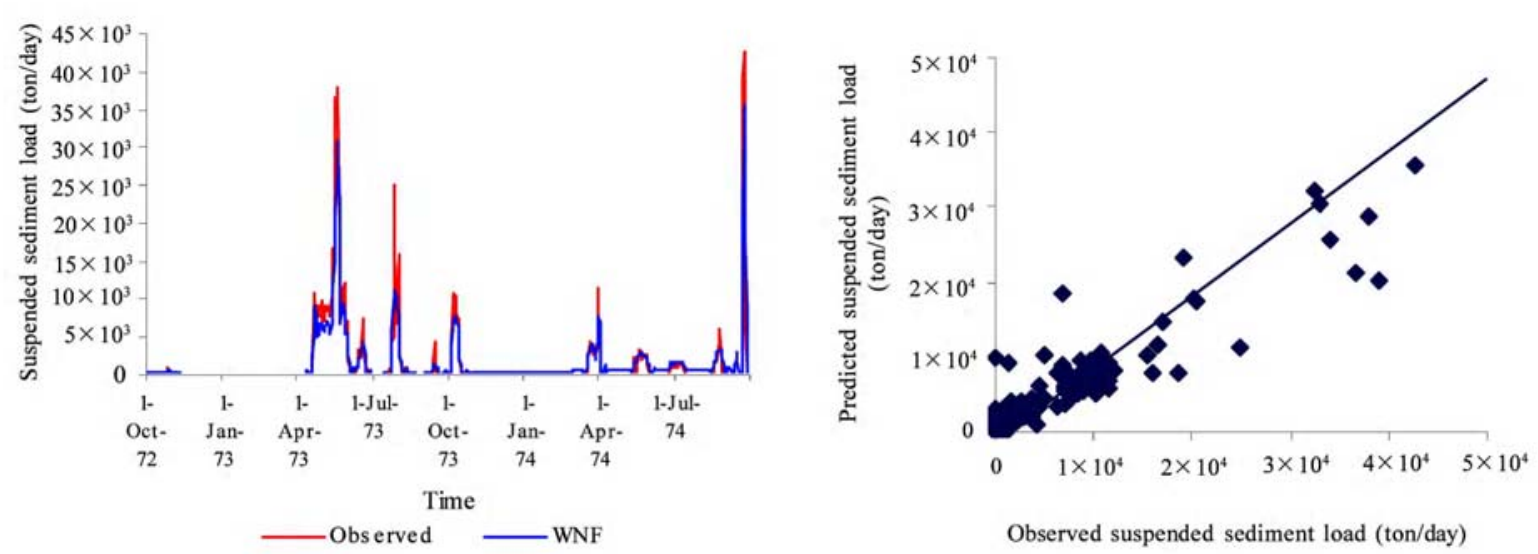

Fig. 8: Observed and predicted SSL using WNF model in verification period
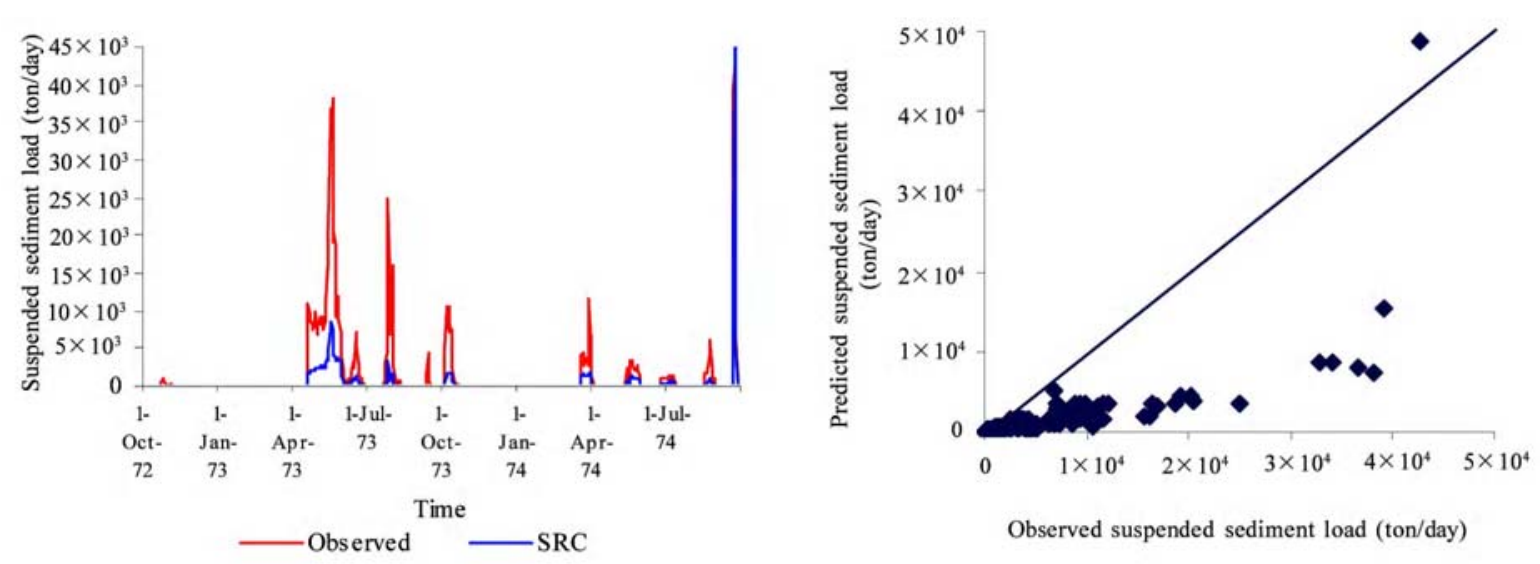

Fig. 9: Observed and predicted SSL using SRC model in verification period 


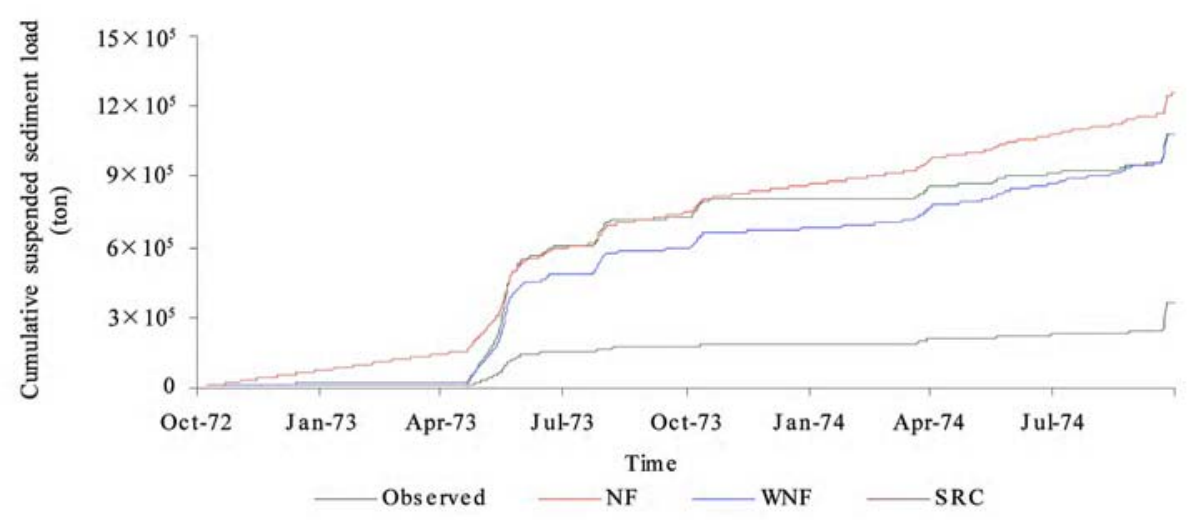

Fig. 10: Measured and estimated cumulative SSL for verification period

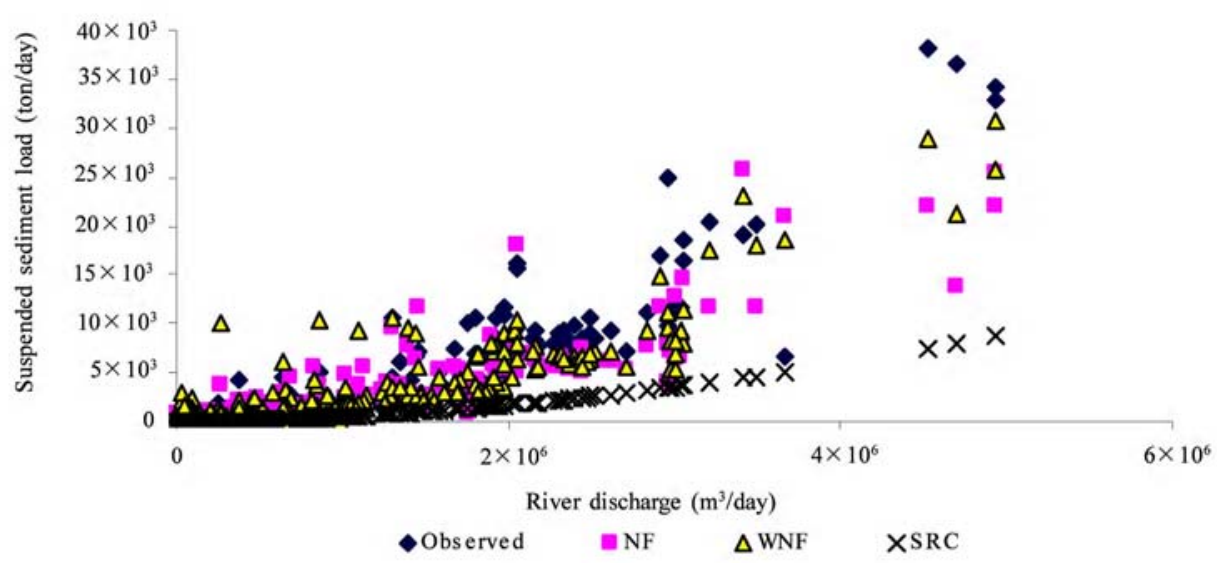

Fig. 11: NF, WNF and SRC performances in hysteresis phenomenon modeling for verification period

Prediction of high suspended sediment load values

In Table 5, the NF, WNF and SRC performances in SSL prediction have shown in verification period for values greater than 12000 (ton/day). According to the Table 5, the amount of $R^{2}$, SSE and RMSE for WNF model are $0.21,1.28 \times 10^{9}$ and 8664.8 , respectively. The proposed WNF model was able to improvement of RMSE values of NF and SRC models by about $40.1 \%$ and $55 \%$, respectively.

\section{Cumulative suspended sediment load estimation}

Estimation of cumulative suspended sediment load which is an essential component in any reservoir engineering problems was also considered as another comparison criterion. The actual cumulative SSL in testing period was 1077361 ton. It was estimated 1253370, 1083997 and 362204 ton by NF, WNF and SRC models, respectively. The NF and WNF models have overestimated by $16.3 \%$ and $0.6 \%$, respectively, while
SRC has underestimated by $66.4 \%$. Observed and estimated cumulative SSL for the verification period are shown in Fig. 10. It is clear that the cumulative SSL estimated by the WNF model is much closer to the actual values than the other models. The SRC technique has quite underestimated.

\section{Hysteresis simulation}

In the scatter plot of river flow discharge and sediment, after some values, a decrease in suspended sediment data is obvious with the increasing river discharge. This property is known as hysteresis and in application, it may come problem for hydrologists, because it denotes to a complicated and unpredicted relation between the suspended sediment and river flow. Tawfik et al. (1997) and Cigizoglu (2004) mentioned this issue and illustrated the various models performances in capturing this event. The NF, WNF and SRC performances in hysteresis phenomenon 
regeneration for testing period are shown in Fig. 11. As it is seen, NF and WNF models simulated the hysteresis event better than SRC method. The NF and WNF models simulated the hysteresis form and its modeling rather unlike than the observed data. The SRC approach was not able in hysteresis regeneration. This technique presents sediment rising by increasing the river flow in all conditions, because of employing a power law relation between them. The Hysteresis phenomenon is observed in the gauging station, strongly suggests that the progressive decline mechanism is dominant in sediment supply in the watershed. The hystersis trend of floods owing to the washout of fine loose material from basin. A postulated cause of hysteresis in the study area is a depletion of available sediment before the water discharge has peakeG]

\section{CONCLUSION}

In this study a new model by conjunction of wavelet analysis and NF approach was applied to daily suspended sediment load prediction in a gauging station in the USA. In the best of the authors' knowledge, this paper is the first application of wavelet-neuro-fuzzy hybrid model for prediction of SSL. In the provided WNF model, at first the observed time series of river discharge and suspended sediment load were decomposed to some sub-time series at different scales by discrete wavelet analysis. Then, effective sub-time series were summed together to obtain useful river discharge and SSL time series in prediction. In the WNF model, selection of appropriate decomposed time series is important in model performance. Afterwards, these total time series were imposed as inputs to the NF model for SSL prediction in one day ahead. The paper presents a comparative study on convenient classic and new generation hybrid intelligence approaches in SSL modeling. Therefore, it will be of particular utility to researchers that require time-series of SSL, but do not have the resources to support sampling or turbidity monitoring and are deciding between various models that predict the needed data from discharge values. This research prepares prediction benchmarks for SSL prediction in the type of numerical and visual contrast between NF, WNF and SRC models. Results indicate that the WNF model is suitable in predictions and improve the NF and SRC performances. Also, the WNF model can satisfactory estimate cumulative suspended sediment load and predict high SSL values by this model show better fitting to the observed data than the other models. The NF approach is in reasonable agreement with the actual SSL data than the SRC technique, but the errors demonstrate that some contributions of the physics are disguised. WNF model goes someway towards including this unknown physics and thus improve the prediction accuracy. Non-stationary time series wavelet decomposition into various sub-series prepares an interpretation of the signal construction and extracts important knowledge about its history with the employ of just a few coefficients. The WNF model considers periodic and stochastic characteristics of suspended sediment phenomenon and may provide suitable constructions not clearly seen in the suspended sediment event. Data pre-processing technique warrants further investigation. In fact, it should be noted that in general and in Pecos River basin in particular, river discharge and SSL time series are characterized by high non-linearity and non-stationarity. NF models may simply be unable to cope with these two different features if preprocessing of the input and/or output data is not performed. Tests undertaken on data preprocessed using a wavelet transformation showed that the best results were obtained with the WNF model. Overall these results provide evidence of the promising role of combining data clustering and discrete wavelet transforms in SSL prediction. The results illustrated the advantage of WNF model to NF approach in simulation of suspended sediment time series. Reasonable contributions are presented to the water resources and environmental engineering literature by this article. However, more study should be conducted to achieve a confident hypothesis in this particular field until WNF approach be a feasible and reliable model in suspended sediment time series simulation. In order to complete the current research, it is suggested to model the SSL process by considering other variables (e.g. temperature or precipitation intensity). Also as a plan for the future study, the presented approaches can be used to simulate monthly and event based SSL time series.

\section{Appendix}

The correlation coefficient $(R)$ between two variables $x$ and $y$, whose $n$ pairs are available, is defined as:

$R=\frac{\sum_{i=1}^{n}\left(x_{i}-\bar{x}\right)\left(y_{i}-\bar{y}\right)}{\sqrt{\sum_{i=1}^{n}\left(x_{i}-\bar{x}\right)^{2} \sum_{i=1}^{n}\left(y_{i}-\bar{y}\right)^{2}}}$ 
Where, the bar denotes the mean of variable. Determination coefficient, SSE and RMSE are defined as:

$$
\begin{aligned}
& R^{2}=1-\frac{\sum_{i=1}^{n}\left(S_{i(\text { measured })}-S_{i(\text { predicted })}\right)^{2}}{\sum_{i=1}^{n}\left(S_{i(\text { measured })}-S_{i(\text { mean })}\right)^{2}} \\
& S S E=\sum_{i=1}^{n}\left(S_{i(\text { measured })}-S_{i(\text { predicted })}\right)^{2} \\
& R M S E=\sqrt{\frac{\sum_{i=1}^{n}\left(S_{i(\text { measured })}-S_{i(\text { predicted })}\right)^{2}}{n}}
\end{aligned}
$$

Which, $S$ is suspended sediment load and $n$ is the number of data points.

\section{REFERENCES}

Addison, P. S.; Murrary, K. B.; Watson, J. N., (2001). Wavelet transform analysis of open channel wake flows. J. Eng. Mechanic., 127 (1), 58-70 (13 pages).

Altun, H.; Bilgil, A.; Fidan, B. C., (2007). Treatment of multidimensional data to enhance neural network estimators in regression problems. Expert Sys. Appl., 32 (2), 599-605 (13 pages).

Asselman1, N. E. M., (2000). Fitting and interpretation of sediment rating curves. J. Hydro., 234, 228-248 (13 pages).

Aqil, M.; Kita, I.; Yano, A.; Nishiyama, S., (2007). Analysis and prediction of flow from local source in a river basin using a neuro-fuzzy modelling tool. J. Environ. Manage., 85 (1), 215223 (13 pages).

Bandyopadhyay, G.; Chattopadhyay, S., (2007). Single hidden layer artificial neural network models versus multiple linear regression model in forecasting the time series of total ozone. Int. J. Environ. Sci. Tech., 4 (1), 141-149 (9 pages).

Brown, M.; Harris, C., (1994). Neuro-fuzzy adaptive modelling and control. Prentice-Hall, Upper Saddle River, New Jersey.

Chang, I. P.; Lin, G. Y., (2007). Fuzzy logic design of the SI engine air-fuel ratio controller., Proceedings of 2007 CACS International Automatic Control Conference. National Chung Hsing University, Taichung, Taiwan.

Chuang, C. C.; Jeng, J. T.; Tao, C. W., (2009). Hybrid robust approach for TSK fuzzy modeling with outliers. Expert Sys. Appl., 36 (5), 8925-8931 (13 pages).

Cigizoglu, H. K., (2004). Estimation and forecasting of daily suspended sediment data by multi layer perceptrons. Adv. Water Resour., 27 (2), 185-195 (13 pages).

Daubechies, I., (1990). The wavelet transform, time-frequency localization and signal analysis. IEEE T. Inform. Theory, 36 (5), 961-1005 (45 pages).

Daubechies I., (1992). Ten lectures on wavelets. CSBM-NSF Series Appl. Math., No. 61. SIAM Publi.; 357.

Firat, M.; Güngör, M., (2008). Hydrological time-series modelling using an adaptive neuro-fuzzy inference system. Hydro. Proc., 22 (13), 2122-2132 (13 pages).

Foufoula-Georgiou, E.; Kumar, P., (1995). Wavelet in Geophysics, Academic Press, New York, 337.
Hadji Hosseinlou, M.; Sohrabi, M., (2009). Predicting and identifying traffic hot spots applying neuro-fuzzy systems in intercity roads. Int. J. Environ. Sci. Tech., 6 (2), 309314 (13 pages)

Hidalgo, D.; Castillo, O.; Melin, P., (2009). Type-1 and type2 fuzzy inference systems as integration methods in modular neural networks for multimodal biometry and its optimization with genetic algorithms. Inform. Sci., 179 (13), 2123-2145 (13 pages).

Jang, J. S. R., (1993). ANFIS: Adaptive network based fuzzy inference system. IEEE T. Syst.Man. Cybernetion, 23 (3), 665-683 (13 pages).

Jang, J. S. R.; Sun, C. T., (1995). Neuro-fuzzy modelling and control, in: Proceedings IEEE, 83, 378-406 (13 pages).

Jang, J. S. R; Mizutani, C. T. S. E, (1996). Neuro-fuzzy and soft computing. Pearson plc, 614.

Jaradat, M. A. K.; Al-Nimr, M. A.; Alhamad, M. N., (2008). Smoke modified environment for crop frost protection: A fuzzy logic approach. Comput. Electron. Agr., 64 (2), 104110 (13 pages).

Kim, T. W.; Valdes, J. B., (2003). Nonlinear model for drought forecasting based on a conjunction of wavelet transforms and neural networks. J. Hydro. Eng., 8 (6), 319-328 (13 pages).

Kisi, O.; Haktanir, T.; Ardiclioglu, M.; Ozturk, O.; Yalcin, E.; Uludag, S., (2008). Adaptive neuro-fuzzy computing technique for suspended sediment estimation. Adv. Eng. Softw., 40 (6), 438-444 (13 pages).

Labat, D.; Ababou, R.; Mangin, A., (2000). Rainfall-runoff relation for karstic spring. Part 2: Continuous wavelet and discrete orthogonal multi resolution analyses. J. Hydro., 238 (3-4), 149-178 (13 pages).

Labat, D., (2005). Recent advances in wavelet analyses: Part 1: A review of concepts. J. Hydro., 314 (1-4), 275-288 (13 pages).

Legates, D. R.; McCabe, Jr., (1999). Evaluating the use of goodness-of-fit measures in hydrologic and hydroclimatic model validation. Water Resour. Res., 35 (1), 233-241 (13 pages).

Lohani, A. K.; Goel, N. K.; Bhatia, K. K., (2007). Deriving stage-discharge-sediment concentration relationships using fuzzy logic. Hydro. Sci. J., 52 (4), 793-807 (13 pages).

Lopez, J.; Cembrano, G.; Cellier, F. E., (1996). Time series prediction using fuzzy inductive reasoning: A case study, Proc. ESM’96, European Simulation Multi Conference, Budapest, Hungary, 765-770 (13 pages).

Mallat, S. G., (1989). A theory for multi resolution signal decomposition: The wavelet representation. IEEE T. Pattern Anal., 11 (7), 674-693 (13 pages).

Mallat, S. G., (1998). A wavelet tour of signal processing, Academic, San Diego, 557.

Masters, T., (1993). Practical neural network recipes in $\mathrm{C}++$. San Diego (CA): Academic Press.

Mirbagheri, S. A.; Tanji, K. K.; Krone, R. B., (1988a). Sediment characterization and transport in Colusa Basin Drain. J. Environ. Eng., 114 (6), 1257-1273 (13 pages).

Mirbagheri, S. A.; Tanji, K. K.; Krone, R. B., (1988b). Simulation of suspended sediment in colusa basin drain. J. Environ. Eng., 114 (6), 1274-1293 (13 pages).

Morgan, R. P. C., (1995). Soil erosion and conservation, $2^{\text {nd. }}$ Ed., Longman, London. 
Morris, G. L.; Fan, J., (1997). Reservoir sedimentation handbook. McGraw-Hill, New York.

Nash, J. E.; Sutcliffe, J. V., (1970). River flow forecasting through conceptual models part I- a discussion of principles. J. Hydro., 10 (3), 282-290 (13 pages).

Nasiri, F.; Maqsood, I.; Huang, G.; Fuller, N., (2007). Water quality index: A fuzzy river-pollution decision support expert system. J. Water Resour. Plan. Manage., 133 (2), 95-105 (13 pages).

Nayak, P. C.; Sudheer, K. P.; Rangan, D. M.; Ramasastri, K. S., (2004). A neuro-fuzzy computing technique for modeling hydrological time series. J. Hydro., 291 (1-2), 52-66 (13 pages).

Nguyen T. J.; Kok, J. L.; Titus, M. J., (2007). A new approach to testing an integrated water systems model using qualitative scenarios. Environ. Model. Softw., 22 (11), 1557-1571 (14 pages).

Nourani, V.; Mogaddam, A. A.; Nadiri, A. O., (2008a). An ANNbased model for spatiotempral groundwater level forecasting. Hydrol. Process, 22 (26), 5054-5066 (13 pages).

Nourani, V.; Alami, M. T.; Aminfar, M. H., (2008b). A combined neural-wavelet model for prediction of Ligvanchai watershed precipitation. Eng. Appl. Artif. Intel., 22 (3), 466-472 (7 pages).

Nourani, V.; Singh, V. P.; Delafrouz, H., (2009). Three geomorphological rainfall-runoff models based on the linear reservoir concept. Catena, 76 (3), 206-214 (9 pages).

Ocampo-Duque, W.; Schuhmacher, M.; Domingo, J. L., (2007). A neural-fuzzy approach to classify the ecological status in surface waters. Environ. Pollut., 148 (2), 634-641 (8 pages).

Osowski, S.; Garanty, K., (2007). Forecasting of the daily meteorological pollution using wavelets and support vector machine. Eng. Appl. Artif. Intel., 20 (6), 745-755 (11 pages).

Partal, T.; Kisi, O., (2007). Wavelet and neuro-fuzzy conjunction model for precipitation forecasting. J. Hydro., 342 (1-2), 199212 (14 pages).

Pasquini, A.; Depetris, P., (2007). Discharge trends and flow dynamics of South American rivers draining the southern Atlantic seaboard: An overview. J. Hydro., 333 (2-4), 385-399 (15 pages).

Rajaee, T.; Mirbagheri, S. A., (2009). Suspended sediment modelling in rivers using ANNs. Accepted in "J. Fac. Eng., Ferdowsi University of Mashhad, Iran”.

Rajaee, T.; Mirbagheri, S. A.; Zounemat-Kermani, M.; Nourani, V., (2009). Daily suspended sediment concentration simulation using ANN and neuro-fuzzy models. Sci. Total Environ., 407 (17), 4916-4927 (12 pages).
Rene, E. R.; Kim, J. H.; Park, H. S., (2008). An intelligent neural network model for evaluating performance of immobilized cell biofilter treating hydrogen sulphide vapors. Int. J. Environ. Sci. Tech., 5 (3), 287-296 (10 pages).

Sarma, J. N., (1986). Sediment transport in the Burhi Dihing River, India. In: Hadley, R. F. (Ed.). Drainage basin sediment delivery, IAHS publication, 159, 199-215.

Szilagyi, J.; Katul, G. G.; Parlange, M. B.; Albertson, J. D.; Cahill, A. T., (1996). The local effect of intermittency on the inertial subrange energy spectrum of the atmospheric surface layer. Bound. Lay. Meteorol., 79 (1-2), 35-50 (16 pages).

Tawfik, M.; Ibramhim, I.; Fahmy, H., (1997). Hysteresis sensitive neural network for modeling rating curves. J. Comput. Civil Eng., 11 (3), 206-211 (6 pages).

Tayfur, G.; Ozdemir, S.; Singh, V. P., (2003). Fuzzy logic algorithm for runoff-induced sediment transport from bare soil surfaces. Adv. Water Resour., 26 (12), 1249-1256 (8 pages).

Tuzkaya, G.; Gülsün, B., (2008). Evaluating centralized return centers in a reverse logistics network: An integrated fuzzy multi-criteria decision approach. Int. J. Environ. Sci. Tech., 5 (3), 339-352 (14 pages).

Tuzkaya, G.; Ozgen, A.; Ozgen, D.; Tuzkaya, U. R., (2009). Environmental performance evaluation of suppliers: A hybrid fuzzy multi-criteria decision approach. Int. J. Environ. Sci. Tech., 6 (3), 477-490 (14 pages).

Verstraeten, G.; Poesen, J., (2001). Factors controlling sediment yield from small intensively cultivated catchments in a temperate humid climate. Geomorphology, 40 (1-2), 123-144 (22 pages).

Wang, L. X., (1994). Adaptive fuzzy systems and control. design and stability analysis. PTR Prentice Hall.

Wang, W.; Ding, J., (2003). Wavelet network model and its application to the prediction of hydrology. Nat. Sci., 1 (1), 67-71 (5 pages).

Wei, A. L.; Zeng, G. M.; Huang, G. H.; Liang, J.; Li, X. D., (2009). Modeling of a permeate flux of cross-flow membrane filtration of colloidal suspensions: A wavelet network approach. Int. J. Environ. Sci. Tech., 6 (3), 395-406 (12 pages).

Yuan, F.; Miyamoto, S.; Anand, S., (2007). Changes in major element hydrochemistry of the Pecos River in the American Southwest since 1935. Appl. Geochem., 22 (8), 1798-1813 (16 pages).

Zounemat-Kermani, M.; Teshnehlab, M., (2008). Using adaptive neuro-fuzzy inference system for hydrological time series prediction. Appl. Softw. Comput., 8 (2), 928-936 (9 pages).

AUTHOR (S) BIOSKETCHES

Rajaee, T., Ph.D., Department of Civil Engineering, K. N. Toosi University of Technology, Tehran, Iran. Email: rajaee@alborz.kntu.ac.ir

Mirbagheri, S. A., Ph.D., Associate Professor, Department of Civil Engineering, K. N. Toosi University of Technology, Tehran, Iran. Email: mirbagheri@kntu.ac.ir

Nourani, V., Ph.D., Associate Professor, Faculty of Civil Engineeing, University of Tabriz, Tabriz, Iran. Email: nourani@tabrizu.ac.ir

Alikhani, A., Ph.D., Assistant Professor, Department of Civil Engineering, Universit of Qom, University, Qom, Iran. Email: dramiralikhani@yahoo.com

How to cite this article: (Harvard style)

Rajaee, T.; Mirbagheri, S. A.; Nourani, V.; Alikhani, A., (2009). Prediction of daily suspended sediment load using wavelet and neurofuzzy combined model. Int. J. Environ. Sci. Tech., 7 (1), 93-110. 